VARIA 



\title{
PREJUICIOS HISTORIOGRÁFICOS SOBRE LAS VERDADERAS CAUSAS DE LA GUERRA DEL PELOPONESO
}

\author{
César Sierra Martín* \\ Universitat Autònoma de Barcelona
}

\begin{abstract}
RESUMO: Neste trabalho, discutiremos duas tendências historiográficas ao redor das verdadeiras causas da Guerra do Peloponeso. Nesse sentido, a presença de uma tendência a favor e outra contra a opinião de Tucídides parece-nos uma abordagem obsoleta que precisa ser superada para o alcance de novas conclusões e a revitalização do debate.
\end{abstract}

PALAVRAS-CHAVE: Tucídides; Diodoro; Guerra do Peloponeso; causas.

\section{Tucídides mythistoricus}

buen seguro que muchos piensan que poco puede decirse a estas alturas sobre la famosa verdadera causa de la Guerra del Peloponeso. No cabe duda de que el análisis ofrecido por Tucídides (I. 23. 6; I. 88) supuso un punto de inflexión historiográfico al dibujar unas motivaciones distintas a las que oficialmente circulaban en la época. Según el historiador fue el miedo de Esparta al creciente poderío ateniense el principal catalizador del conflicto; mientras que los supuestos desencuentros entre Atenas, Corinto y otras póleis a raíz del conflicto en Corcira primero (Th. I. 24-55) y en Potidea después (Th. I. 56-66) quedaban en meros pretextos. Merece la pena recoger el pasaje donde Tucídides expone dicha cuestión:

^cesar.sierra@e-campus.uab.cat 


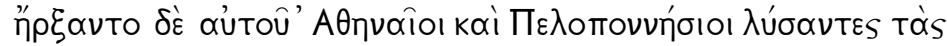

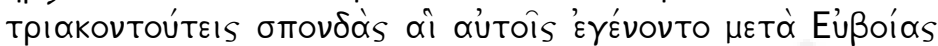

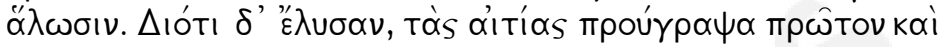

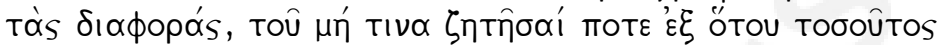

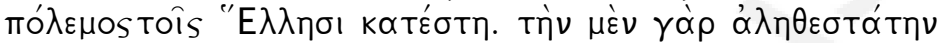

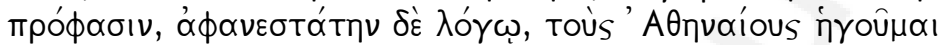

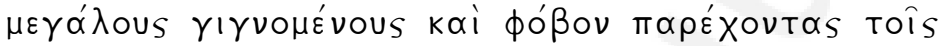

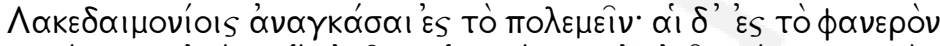

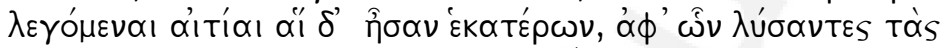

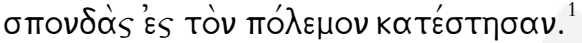

Desde nuestro punto de vista, Tucídides propone una cuestión de gran relevancia: sólo el historiador, mediante la interpretación de las evidencias, es capaz de discernir correctamente el fondo de los sucesos. En otras palabras, Tucídides asocia a la figura del historiador ese hálito de credibilidad que se extiende hasta nuestros días. ${ }^{2}$ Lo cierto es que el pasaje anterior constituye uno de los puntos que mayor atención ha despertado en los estudiosos modernos de Tucídides. El análisis terminológico del pasaje enfatiza la distinción entre los pretextos (próphasis) y la causa subyacente (tás aitías), señalando que ello supone todo un hito en la literatura griega. ${ }^{3}$

\footnotetext{
${ }^{1}$ Texto griego en Thucydides. "Historiae" in two volumes. Ed. H. Stuart-Jones and J. E. Powell. Oxford: Oxford University Press, 1942/ Tucídides. Historia de la guerra del Peloponeso. Trad. J. J. Torres-Esbarranch. Madrid: Gredos, 2000: Th. I. 23. 4-6 - "[La guerra] la comenzaron los atenienses y los peloponesios al romper el tratado de paz de treinta años que habían concertado después de la conquista de Eubea. Para explicar por qué rompieron he expuesto en primer lugar las razones de esta ruptura y las diferencias que la ocasionaron, a fin de que nunca nadie se pregunte por qué se produjo entre los griegos una guerra tan importante. La causa más verdadera, aunque la que menos se manifiesta en las declaraciones, pienso que la constituye el hecho de que los atenienses al hacerse poderosos e inspirar miedo a los lacedemonios les obligaron a luchar. Pero las razones declaradas públicamente, por las cuales rompieron el tratado y entraron en guerra, fueron las siguientes por parte de cada bando".

${ }^{2}$ Credibilidad que se alcanza tras esgrimir de forma crítica las evidencias de las que se dispone. Cf. Sierra, op. cit., 2012b, p. $79-84$ (con bibliografía).

${ }^{3}$ El interés por las verdaderas causas de la guerra del Peloponeso según Tucídides parte, como mínimo, desde el Humanismo (s. XV); cf. Hoekstra, op. cit., p. 49. Sin embargo, los historiadores estudiaron especialmente el tema hacia la mitad del siglo pasado centrándose en la terminología que hemos señalado: Gomme, op. cit., p. 152-157; Adcock, op. cit., p. 2-12; Kirkwood, op. cit., p. 37-61; Pearson, op. cit., p. 205-223; Momigliano, op. cit., p. 151-167; Sealey, op. cit., p. 1-12; Andrewes, op. cit., p. 223-239; de Romilly, op. cit., p. 24 et seq. Más adelante surgieron influyentes aproximaciones como Kagan, op. cit.; Meiggs, op. cit., 1972, p. 200-201; St. Croix, op.
} 
El mérito de Tucídides fue pasar de la narración de los eventos al análisis de las causas y las consecuencias de los mismos, iniciando lo que podríamos denominar un estado de opinión en torno a un problema histórico. ${ }^{4}$ Por éste y otros motivos, en la actualidad Tucídides ejerce un fuerte magnetismo sobre los historiadores. Recientemente, el eminente historiador Josiah Ober resumía cómo el estudio de la historiografía clásica y de la obra de Tucídides le ayudó a comprender mejor el pensamiento político moderno:

The ancient world - and especially the world of the classical Greek poleis - seemed to offer the raw materials for understanding politics. Not surprisingly, reading Thucydides was a revelation. I realized, as have so many others, that Thucydides' narrative of the events of the Peloponnesian war was the product of a profoundly powerful intelligence working at the descriptive and analytical sides of the power and legitimacy equation. ${ }^{5}$

Los comentarios personales de Ober acerca del efecto que produjo la lectura de Tucídides en el desarrollo de su carrera intelectual nos acercan a ese magnetismo al que nos referíamos. Actualmente, la obra de Tucídides se contempla en muchos casos como una inspiración, lo cual no es censurable pero sí que empaña a menudo las aproximaciones de algunos autores. En este sentido, algunos historiadores apoyados en el pasaje que nos ocupa y en algunos otros, afirman que Tucídides supuso un corte historiográfico respecto a sus predecesores. ${ }^{6}$ En alguna cuestión puede ser cierto pero no lo entendemos así para el conjunto de su obra, pues aunque el mismo Tucídides intente desmarcarse veladamente de Heródoto (Th. I. 22. 4; I. 97) y explícitamente de Helánico de Lesbos (Th. I. 97), su obra le debe mucho a la historíe jonia. ${ }^{7}$

cit., p. 51-63; Rawlings, op. cit.; Connor, op. cit., p. 32-33. El debate continúa en la actualidad de tal forma que resulta difícil recopilar toda la bibliografía por lo que remitimos a los trabajos autorizados de Hornblower, op. cit., p. 64-66; Lewis, op. cit., p. 370-432 y a las recientes contribuciones de Shanske, op. cit., p. 37-40; Sierra, op. cit., 2012a, p. 81-106 y Stadter, op. cit., p. 55, con bibliografía.

${ }^{4}$ También Heródoto centró su análisis histórico en las causas y consecuencias de los distintos sucesos que explica en su Historia pero creemos que Tucídides lo hizo de forma más evidente. La cuestión se analiza magistralmente en Momigliano, op. cit., p. 153-158.

${ }^{5}$ Cf. Ober et alii, op. cit., p. 1-2.

${ }^{6}$ Cf. Darbo-Peschanski, op. cit., p. 37-38.

${ }^{7}$ Cf. Crane, op. cit.; Martínez-Lacy, op. cit., p. 79; Rengakos, op. cit., p. 279-300 y Sierra, op. cit., 2012b. 
Sin embargo, no todo han sido elogios para Tucídides y sus verdaderas motivaciones de la guerra y es que a principios del siglo XX se erigió una voz discordante, el Thucydides mythistoricus de Cornford. Se puede decir sin miedo a equivocarse que la obra de Cornford pretende combatir la tendencia historiográfica favorable a Tucídides. ${ }^{8}$ Desde el primer capítulo, Cornford expone que, a la luz de las explicaciones de Tucídides, ni Atenas ni Esparta tenían motivos suficientes para iniciar la guerra. Nuestro autor distingue tres motivos más, añadidos al análisis de Tucídides, que deben tenerse en cuenta, a saber: los motivos personales de Pericles para iniciar una guerra, el conflicto "racial" subyacente entre dorios y jonios y, finalmente, el conflicto ideológico entre democracia y oligarquía. ${ }^{9}$ A su vez, Cornford resume las tesis de Tucídides en dos: el miedo de Esparta al creciente poderío ateniense y el hecho de que aquella se viera forzada a entrar en guerra por sus aliados de la Liga Peloponesia. Ésta última cuestión es la que preocupó a Cornford por encima de todo, pues se mostró conforme con la idea de que Esparta entrara en guerra presionada por sus aliados pero lo achacó principalmente a una coyuntura económica concreta, ejemplarizada a través del conocido "Edicto de Mégara". ${ }^{10}$ En consecuencia, en el tercer capítulo, Cornford desarrolla lo que considera el centro de la cuestión, el "Edicto de Mégara", que Tucídides recoge pero quizás no desarrolla en su justa medida. Afortunadamente, podemos valorar el contenido y las consecuencias de dicho bando a través de fuentes como Aristófanes, Diodoro de Sicilia y Plutarco. Ciertamente, el énfasis que puso Cornford y otros historiadores de su época en el "Edicto de Mégara" propició que se introdujeran nuevos parámetros en el análisis moderno sobre las causas de la Guerra del Peloponeso. ${ }^{11}$ Así, recogiendo el testigo de Cornford, analizaremos la versión de Diodoro, atribuida a Éforo de Cime (s. IV a.C.), y que constituye una alternativa a

\footnotetext{
${ }^{8}$ Desconocemos si otros autores también se mostraron reacios al análisis de Tucídides, pero, sin duda, creemos que Cornford fue el más beligerante en este punto.

${ }^{9}$ Cf. Cornford, op. cit., p. 3-4. Nótese que hemos mantenido el término "racial" respetando las palabras del propio Cornford, pero actualmente hablaríamos más bien de un conflicto étnico. Por otro lado, el énfasis en la diferencia ideológica tiene su eco en la propia Inglaterra de la época de Cornford, dividida entre los Whig y los Tory (cf. Cornford, op. cit., p. 10).

${ }^{10}$ Cf. Cornford, op. cit., p. 8 et seq.

${ }^{11}$ Ello puede advertirse en Grundy, op. cit., y Kagan, op. cit., que siguen la senda de Cornford pero con muchos matices en cuanto a las conclusiones se refiere.
} 
Tucídides en la explicación de las causas de la Guerra del Peloponeso. Paralelamente, realizaremos una lectura de ambas versiones, explorando los puntos en común y las divergencias. Finalmente, mostraremos que la polarización del debate moderno en torno a las verdaderas causas de la guerra parte de una serie de prejuicios historiográficos que empañan la correcta armonización de ambas tradiciones.

\section{La otra versión de los hechos: Diodoro, Éforo y el "Edicto de Mégara"}

Antes de valorar las distintas impresiones historiográficas sobre el "Edicto de Mégara" debemos plantear mínimamente en qué consistió y qué fuentes tenemos a nuestra disposición para acercarnos a su contenido. Tenemos suficientes testimonios que recogen el edicto o edictos de Mégara, comenzando por el mismo Tucídides, quien lo menciona directamente en dos ocasiones (Th. I. 67. 4; I. 144. 2) y quizás veladamente en otra (Th. I. 42. 2). ${ }^{12}$ La primera mención explícita del "Edicto de Mégara" se produce durante el famoso debate que tuvo lugar en Esparta entre los agraviados por Atenas (Corinto, Mégara, Egina, etc) y la propia Atenas, acaecido tras el conflicto en Potidea. En esta tesitura, Tucídides explica que los aliados de Esparta expusieron sus quejas y motivos para que la Liga Peloponesia declarara nula la Paz de los Treinta Años y se entrara en guerra. Sobresalió sobre el resto de quejas la de Mégara, que expuso cómo los atenienses les impedían la entrada a los puertos del imperio ateniense y el acceso al mercado Ático ${ }^{13}$ (Th. I. 67. 4). La mención indirecta surge a raíz del relato sobre el conflicto de Corcira y se centra en un discurso de los corintios, quienes

\footnotetext{
${ }^{12}$ A continuación sólo analizaremos una de las dos menciones explícitas al "Decreto de Mégara”, el pasaje Th. I. 144. 2 lo reservamos para el último apartado. Por otra parte, la datación exacta del edicto es una cuestión compleja, pero se estima que sucedió poco antes del estallido de la guerra; Gomme, op. cit., p. 226-227 y Hornblower, op. cit., p. 110-111.

${ }^{13}$ En el texto de Tucídides se hace referencia a los puertos (liménon) dominados por Atenas (tôn en têi Athenaíon archê). Nosotros lo acercamos al lenguaje moderno mediante la palabra "imperio", en referencia a todos aquellos puertos pertenecientes a la Liga de Delos que Atenas controlaba. Al respecto la bibliografía es inabarcable pero proponemos el trabajo de Finley, op cit., p. 60-84 y Cataldi, op. cit., p. 117-159, una aproximación completa a las fuentes primarias y secundarias y al proceso mediante el cual Atenas transformó la Liga de Delos en su imperio.
} 
señalan las diferencias que surgieron entre Corinto y Atenas por Mégara, pero no sabemos si se refiere al edicto o a un conflicto anterior (Th. I. 42. 2). ${ }^{14}$ Podemos afirmar sin lugar a dudas que Tucídides conocía los hechos en torno a Mégara y que éstos se presentaron como queja (aitía) particular a Esparta. Algún dato más podemos inferir de Aristófanes, Acharn. 495-540, quien por boca de Diceópolis señala a Pericles como el impulsor del edicto e instigador de la guerra. En esta versión sería Pericles el culpable de impulsar una medida económica que asfixiaría los intereses de los principales aliados de Esparta. Además, Aristófanes mezcla en todo este asunto a la conocida compañera de Pericles, Aspasia, trasladando el problema hacia el terreno personal. ${ }^{15}$

El testigo de Aristófanes lo recogerá siglos después Diodoro, cuya explicación de las causas de la Guerra del Peloponeso no parece seguir la línea de Tucídides. ${ }^{16}$ Según el siciliota, todo se centra en la figura de Pericles y en la lucha facciosa en la propia Atenas. Al parecer, al trasladar el tesoro de la Liga desde Delos hasta Atenas, Pericles fue acusado públicamente de malversación. En paralelo a esta acusación, los adversarios de Pericles también lo involucraron junto al escultor Fidias en una supuesta trama de malversación de fondos destinados a la construcción de la estatua de Atenea. ${ }^{17}$ En esta tesitura, Pericles, aconsejado por un jovencísimo Alcibíades, comienza a barajar la posibilidad de inmiscuir a Atenas en una gran guerra para, de este modo, distraer la atención sobre sus acciones corruptas (Diod. XII. 38-39). La ocasión para llevar a cabo sus proyectos vino a raíz de la aprobación del edicto que nos ocupa. Diodoro lo resume en los siguientes términos:

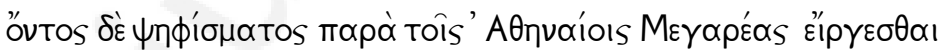

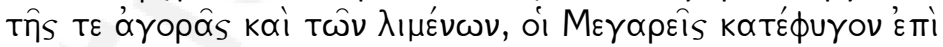

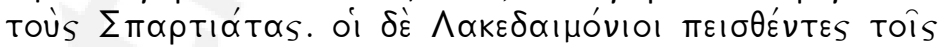

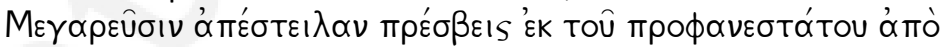

\footnotetext{
${ }^{14}$ Véase principalmente Gomme, op. cit., p. 175-176; Tuplin, op. cit., p. 301-307 y Hornblower, op. cit., p. 85-86.

${ }^{15}$ Un análisis más extenso del testimonio de Aristófanes lo encontramos en St. Croix, op. cit., p. 231-243.

${ }^{16}$ Aunque Diodoro consideraba a Tucídides una fuente veraz (Diod I. 37. 3-4); cf. Sierra, C. Sobre la malevolencia hacia Diodoro en la historiografía moderna. Calíope: presença clássica, Rio de Janeiro (en prensa).

${ }^{17}$ Plutarco recoge una versión similar pero con más detalles personales, Per. 31-33. Recordemos que el propio Plutarco no se consideraba un historiador (Alex. 1. 1) y ello le otorgaba más libertad a la hora de referir los hechos.
} 


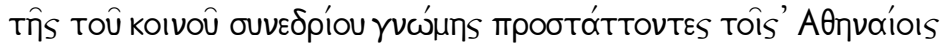

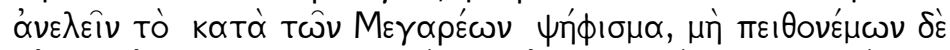

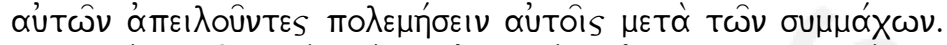

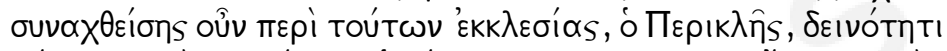

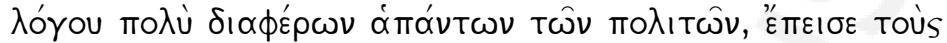

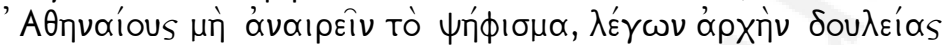

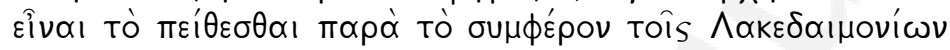

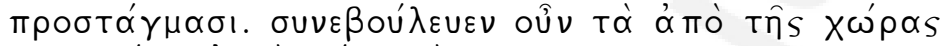

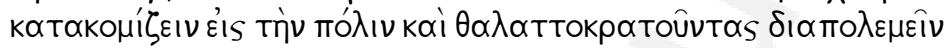
Tois $\sum \pi \alpha \rho$ TIátals. ${ }^{18}$

Según vemos en Diodoro, la cuestión sobre las causas de la guerra gira alrededor de dos cuestiones principales que confluyen de forma independiente: la actuación de Pericles y el "Edicto de Mégara". Sabemos por el propio Diodoro (XII. 41) que esta era la versión defendida por el historiador Éforo de Cime (s. IV a.C.), cuya obra conocemos de forma precaria gracias a la compilación de fragmentos. ${ }^{19}$ La versión que ofrece Plutarco, en su Vida de Pericles 29, no difiere en exceso de la que presenta Diodoro pero todavía es más explícita si cabe. Según Plutarco, Pericles fue el responsable último de la guerra puesto que fue el que con más ardor defendió la vigencia del "Edicto de Mégara" y la política imperialista de Atenas. También sostiene que el líder ateniense acusó públicamente a los megarenses de haber cultivado tierra sagrada; Mégara y el Ática eran

\footnotetext{
${ }^{18}$ Texto griego en Diodorus Siculus. Diodorus of Sicily in twelve volumes with an English translation. Ed. and transl. by C. H. Oldfather. Vol. 4-8. Cambridge, Mass.: Harvard University Press, 1989/ Diodoro de Sicilia. Biblioteca histórica. Trad. J. J. Torres Esbarranch. Madrid: Gredos, 2006: Diod. XII. 39. 4-5 - "Al votar los atenienses un decreto que prohibía a los megarenses el acceso a su mercado y a sus puertos, los megarenses recurrieron a los espartiatas. Los lacedemonios, convencidos por los megarenses, de la manera más abierta enviaron embajadores para que, de acuerdo con la decisión del Consejo común, conminaran a los atenienses a derogar el decreto contra los megarenses, con la amenaza, en caso de que no cedieran, de entrar en guerra contra ellos juntamente con sus aliados. Cuando la Asamblea se reunió para examinar el asunto, Pericles, que aventajaba en mucho a sus conciudadanos por su habilidad oratoria, persuadió a los atenienses a no derogar el decreto, diciéndoles que ceder a las imposiciones de los lacedemonios en contra de sus intereses significaba el comienzo de la esclavitud. Les aconsejó, pues, que transportaran a la ciudad todos los bienes que tenían en los campos y que, en su condición de señores del mar, emprendieran la guerra contra los espartiatas".

${ }^{19}$ Véase la aproximación de Sacks, op. cit., y, recientemente, Parmeggianni, op. cit., y Sulimani, op. cit., p. 57-108.
} 
regiones colindantes, hecho que ha inspirado sugerentes interpretaciones modernas sobre el "Edicto de Mégara". ${ }^{20}$ A su vez, el biógrafo ofrece una sucinta pero interesante narración sobre la rivalidad política que Pericles mantuvo con los sucesores de Cimón, que al igual que éste defendían una política de aproximación a Esparta. ${ }^{21}$ Pese a las aparentes divergencias respecto al relato de Tucídides, ambas versiones no son del todo excluyentes en su conjunto. En este sentido, el "Edicto de Mégara" es consecuencia de la política imperialista de Atenas, que induce a los aliados de Esparta a solicitar abiertamente la guerra. ${ }^{22}$ Un ejemplo paralelo al "Edicto de Mégara" lo hallamos en una famosa serie de decretos que muestra las relaciones comerciales entre Atenas y Metone, en la costa macedonia $\left(I G \mathrm{I}^{2} 57\right) \cdot{ }^{23}$ La excepcional y estratégica posición de Metone en el abastecimiento de madera propició unas peculiares relaciones diplomáticas con Atenas. ${ }^{24}$ Según sabemos por el segundo decreto, Atenas permitió a Metone la compra de una cantidad fija anual de grano directamente a Bizancio, ahorrándose las tasas que el resto de póleis del Egeo debían pagar a los atenienses. ${ }^{25}$ Esta presión económica a la que nos referimos constituye el núcleo de las causas de la Guerra del Peloponeso según la tradición alternativa a Tucídides. En consecuencia, los defensores de las causas económicas de la Guerra del Peloponeso sitúan en el centro del debate al "Edicto de Mégara" mientras que los historiadores que se decantan por el análisis tucidídeo lo relegan a un segundo plano. Por nuestra

${ }^{20}$ Nos referimos a la conocida tesis de St. Croix, op. cit., cap. 3, que relaciona la prohibición de acceder al "Ágora de Atenas" con la profanación de la tierra sagrada por parte de los megarenses. El citado autor relaciona el decreto con un castigo de índole religioso, esgrimiendo testimonios como el de Platón, Leyes 871a, que secundan su teoría. No obstante, como indica Hornblower, op. cit., p. 111, no se destaca especialmente el factor económico del bloqueo a Mégara.

${ }^{21}$ La rivalidad entre ambas facciones también se recoge en Aristóteles Ath. 27, véase el análisis de Podlecki, op. cit., p. 35-45.

${ }^{22}$ Cuestión bien advertida y desarrollada en Finley, op. cit., p. 78-79.

${ }^{23}$ Cf. Meiggs y Lewis, op. cit., p. 176-178 (n. 65) y datación de los decretos (c. 430-425 a.C.) en Mattingly, op. cit., p. 154-165.

${ }^{24}$ De hecho, Atenas mediaba entre Metone y Macedonia a favor de la primera y otorgándole un favor especial respecto al resto de aliados, seguramente con la intención de obtener la madera macedonia más fácilmente (cf. Meiggs, op. cit., 1982, p. 356).

${ }^{25}$ Tasas que no eran en absoluto una minucia como advertimos en la comedia $A r$. V. 655-661. 
parte, no hayamos antagonismo alguno entre ambas versiones, pues la asfixia económica que sufrían los aliados de Esparta nos resulta la prueba palpable de ese creciente poderío que tanto temía Esparta. Al hilo de esta cuestión, parece claro que si Esparta no hubiera intervenido habría terminado por perder la hegemonía sobre sus aliados.

La historiografía ha ofrecido un análisis sesgado sobre esta cuestión puesto que no ha integrado con armonía ambas versiones, pese a los puntos en común que presentan. Lo cierto es que a nivel historiográfico se plantean diversas cuestiones que van más allá del cotejo de los textos que hemos presentado y que se reducen a tomar partido por una versión y, lo más importante, por una fuente literaria. El caso más ejemplar lo hemos abordado a través de la obra de Cornford, quien toma posición a favor de Diodoro y en contra de Tucídides. Sin duda es una postura agresiva que obtuvo un respaldo tibio por parte del mundo académico, que pronto desvió la atención hacia las fuentes que utilizó Diodoro en su versión de los hechos. ${ }^{26}$

Tomemos un ejemplo que nos ayude a poner orden en las ideas y nos permita definir la posición historiográfica contraria a Cornford: el Athenian Empire de Russell Meiggs. Hemos escogido esta obra por su prestigio y porque en muchos aspectos su análisis continúa vigente. ${ }^{27}$ Ciertamente no se pude decir que en la obra de Meiggs se descuide la atención hacia el edicto e incluso se llega a defender que la escasa importancia que Tucídides le presta constituye la vertiente menos atractiva de la obra del ateniense. Sin embargo, Meiggs lo justifica afirmando que fue la reacción exagerada por parte de Tucídides a la postura más popular de su época sobre las causas de la guerra. Finalmente, concluye que aunque Tucídides fuera demasiado lejos en esta postura historiográfica básicamente estaba en lo cierto. ${ }^{28}$ La pregunta que se deriva a continuación cae por su propio peso ¿Por qué no se inserta debidamente el testimonio de Diodoro en el análisis de las causas de la guerra y en la discusión alrededor del "Edicto de Mégara"? La respuesta apunta directamente a la diferencia de prestigio historiográfico entre Tucídides y Diodoro. Ilustrémoslo de nuevo a través de la obra de Meiggs donde encontramos un interesante apéndice titulado "Uso y abuso de Diodoro" y que aborda

\footnotetext{
${ }^{26}$ La obra de Cornford también recibió algún que otro piropo de Momigliano, op. cit., p. 158.

${ }^{27}$ De hecho figura como lectura recomendada y autorizada en los principales manuales sobre historia antigua (cf. Low, op. cit., p. 72).

${ }^{28}$ Cf. todo el desarrollo en Meiggs, op. cit., 1972, p. 203-204 y p. 431.
} 
diez puntos en los que Tucídides y Diodoro no coinciden, especialmente aquellas situaciones donde se abordan recuentos de tropas y recursos. ${ }^{29}$ El argumento que esgrime Meiggs se centra en dibujar la ya resabida y tergiversada "dependencia" de Diodoro respecto a otras fuentes y, en nuestro caso, a Éforo. Todo ello se utiliza con la finalidad de desacreditar a Diodoro como fuente veraz y crítica, lo cual redunda en un descrédito de su versión de las causas de la guerra. ${ }^{30} \mathrm{Al}$ final del apéndice el autor glosa este prejuicio historiográfico a la perfección:

Diodorus was not a critical historian. He was not capable of asking the kind of questions that interest us most about the Athenian empire, nor would he have known where to find the kind of things we want to know. He does, however, fill a few gaps, and it is fair to remember that he is writing a universal history of which the fifth century is a very small part. ${ }^{31}$

La anterior no es en absoluto una opinión aislada y, en relación con el debate alrededor de las causas de la guerra, constituye el contrapunto de la opinión de Cornford. ${ }^{32}$ Por tanto, si la opinión de Cornford desarrolla la tendencia anti-tucidídea, la versión que aporta Meiggs combina el magnetismo tucidídeo del que nos hacíamos eco a través de la opinión de J. Ober junto a una declarada animadversión hacia Diodoro como historiador. Afortunadamente, la historiografía es amplia y diversa en el análisis de las causas de la Guerra del Peloponeso y en las mismas fechas que se publicó la obra de Meiggs encontramos valoraciones como las de G. E. M. de St. Croix, que intenta conjugar ambas versiones, tomando a Tucídides como base del análisis. ${ }^{33}$ No obstante, a inicios de los noventa,

\footnotetext{
${ }^{29}$ Nos referimos al segundo apéndice del Athenian Empire; Meiggs, op.cit., 1972, p. 447-458.

${ }^{30}$ Cf. especialmente Meiggs, op. cit., 1972, p. 451.

${ }^{31}$ Cf. Meiggs, op. cit., 1972, p. 458.

${ }^{32}$ La tendencia historiográfica que definió a Diodoro como un compilar acrítico, la denominada Quellenforschung, tuvo a su principal valedor en E. Schwartz y su famosa entrada "Diodorus" del Paulys Realencyclopädie der classischen Altertumnswissenschaft (cf. Schwartz, op. cit.). Actualmente tiende a remitir, véanse impresiones y bibliografía en Morais-Mota, op. cit., y Sierra, op. cit. (en prensa).

${ }^{33}$ Cf. St. Croix, op. cit., p. 290-291, aunque su interpretación acerca de la prohibición de acceder al Ágora del Ática a los megarenses lo tome de forma literal y no como un bloqueo comercial, lo cual es muy discutible como ya hemos advertido (Lewis, op. cit., p. 376-377).
} 
David M. Lewis ya advertía que la versión de las causas de la guerra recogida en Diodoro y Plutarco no gozaba de gran aceptación en el mundo académico y así permanece, según hemos podido comprobar en los distintos manuales y obras de referencia sobre Tucídides. ${ }^{34}$ A todo esto, a buen seguro que somos numerosos los historiadores que nos preguntamos qué habría pasado si la versión de Diodoro la hubiera recogido Polibio...

\section{Diodoro historicus}

Sabemos positivamente que Diodoro conocía la obra de Tucídides y la valoraba como fuente para la reconstrucción de la Guerra del Peloponeso. De hecho, Diodoro se detiene en la narración de los hechos correspondiente al año 432/ 1 a.C. para informar de lo siguiente:

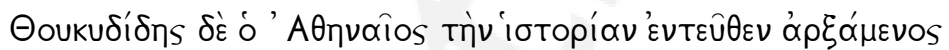

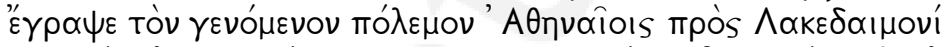

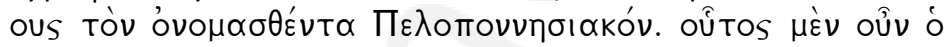

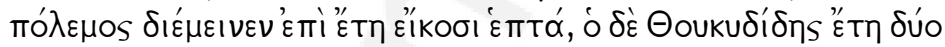

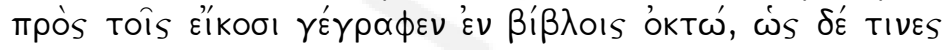

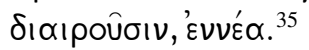

El pasaje resulta interesante porque muestra el grado de conocimiento que Diodoro tenía sobre la obra de Tucídides. En primer lugar, destaca el dato de los ocho libros en que divide la obra y que

${ }^{34}$ Cf. Lewis, op. cit., p. 377 y la confirmación en Badian, op. cit., p. 144-145, donde los motivos económicos ocupan un lugar marginal y no se mencionan las opiniones de Diodoro y Plutarco; Cawkwell, op. cit., p. 20-39, quien realiza una excelente presentación de las diferentes interpretaciones modernas e incluye la cuestión en torno a Mégara pero, paradójicamente, sólo utiliza el testimonio de Tucídides concluyendo que lleva razón en sus argumentos (Ib.:39); Price, op. cit., p. 345 et seq., con un análisis interesante sobre las verdaderas causas de la guerra como elemento rector del libro I de Tucídides pero no consigue abrir el debate hacia otras fuentes y, recientemente, Lendon, op. cit., p. 258-28, que constituye un auténtico panegírico a favor de las verdaderas causas de Tucídides y Tritle, op. cit., p. 36-37, que relaciona el famoso pasaje de Tucídides con los conflictos bélicos modernos.

${ }^{35}$ Diod. XII. 37. 2: "Tucídides, el ateniense, tomando este año como punto de partida de su historia, relató la guerra entre atenienses y lacedemonios conocida como Guerra del Peloponeso. Esta guerra duró de hecho veintisiete años, pero el relato de Tucídides sólo cubrió veintidós, en ocho libros o, según la división efectuada por algunos, en nueve" (J.J. Torres Esbarranch). 
corresponde con la actual división, realizada en la biblioteca de Alejandría. Además, parece que Diodoro conocía otras ediciones de la obra al informarnos de una división alternativa en nueve libros. En segundo lugar, Diodoro delimita tanto la duración de la guerra como el periodo que Tucídides analizó de la misma, demostrando de nuevo un elevado control de sus fuentes. No cabe duda tampoco de que en el siglo I a.C., época en la que escribe Diodoro, Tucídides era un historiador de elevado prestigio solo contemplado críticamente por unos pocos intelectuales, entre ellos Dionisio de Halicarnaso en el Sobre Tucídides. ${ }^{36}$ En consecuencia, podemos especular con la posibilidad de que Diodoro conociera también la famosa "verdadera causa" de la Guerra del Peloponeso de Tucídides y, sin embargo, se decantó por el análisis de Éforo, mostrando personalidad y criterio historiográfico. De la misma forma, Tucídides mostró su criterio al no otorgar gran relevancia a la cuestión alrededor del "Edicto de Mégara", que sin duda conocía, pues consideraba que lo más relevante era el miedo que el poder de Atenas despertaba en Esparta. Lo más curioso del caso es que ambas versiones no son antagónicas sino que en algunos puntos llegan a ser complementarias. $^{37}$

En lo que parecen diferir ambas versiones es en el protagonismo de Pericles. En un principio, Tucídides no parece atribuir a Pericles mucha responsabilidad en la entrada de Atenas en guerra. Es el momento de retomar un pasaje de Tucídides donde se menciona explícitamente la cuestión de los megarenses y cuyo análisis habíamos prometido. Éste nos traslada a los momentos previos de la guerra, en mitad del cruce de acusaciones entre Esparta y Atenas, donde se recoge un famoso discurso de Pericles ante la Asamblea a favor de las posibilidades de Atenas en un hipotético encuentro armado. El discurso toma la forma de respuesta al ultimátum de Esparta, que exigía el levantamiento del asedio de Potidea, la autonomía de Egina y el fin del decreto contra los megarenses (Th. I. 139). Pericles finalizó el discurso en un claro tono desafiante:

\footnotetext{
${ }^{36}$ Recientemente hemos abordado algunos ejemplos de la buena recepción de Tucídides en los círculos intelectuales romanos, sobre todo Cicerón, Sierra, op cit. (en prensa). Además deben consultarse las excelentes precisiones de Samotta, op. cit., p. 345-378.

${ }^{37}$ Ya hemos advertido que el "Edicto de Mégara" es consecuencia de la política imperialista de Atenas.
} 


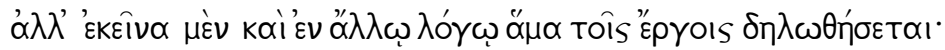

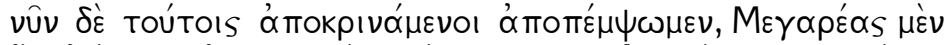

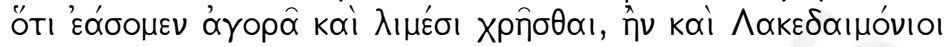

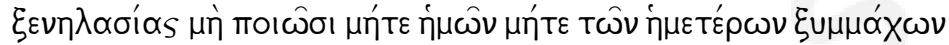
$[\ldots] .^{38}$

La propuesta de Pericles continúa exhortando a sus conciudadanos a no ceder en la política imperialista hasta sus últimas consecuencias, la guerra. La moción de Pericles se aprobó y entonces nos preguntamos: ¿No persuadió Pericles a los atenienses para que no derogaran el decreto y entraran en guerra, tal y como afirma Diodoro? De nuevo apreciamos que ambas versiones no están tan lejos, solo que Tucídides quiere llegar al impulso primitivo que condujo a la guerra, sin entrar en detalles sobre la situación personal de Pericles antes del estallido del conflicto y los agravios particulares de cada bando. Pero, en general, la implicación personal de un líder carismático en el estallido de un conflicto bélico no es una cuestión baladí, pues el empeño de Pericles en Atenas o el de Arquidamo y Estenelaidas en Esparta forman parte del panorama político interno de ambas póleis, que debe tenerse en cuenta a la hora de abordar las causas de la guerra. Por tanto, no rubricamos opiniones como la de A. Momigliano, que tildó de frívolo el supuesto protagonismo de Pericles en el estallido de la guerra. ${ }^{39}$ En cierto modo, no podemos añadir objetivamente argumentos a favor o en contra de la supuesta actuación corrupta de Pericles pero sí debemos recordar que el propio estratego estuvo detrás de una campaña erosiva de desprestigio contra Cimón, el líder conservador de la primera mitad del siglo $\mathrm{V}$ a. C. El apoyo de Cimón a Esparta y los continuos pleitos a los que era sometido por sus rivales acabaron por desgastarlo políticamente (Arist. Ath. 25; Plu. Per. 9) y lo mismo podría decirse de Tucídides de Melesias, otro rival político de Pericles (Plu. Per. 11 et seq.). De esto era plenamente consciente Pericles y por ello no nos parece descabellado pensar que pretendiera distraer la atención mediante un conflicto armado; otra cosa es que calculara adecuadamente la magnitud de la futura guerra. Por

\footnotetext{
${ }^{38}$ Th. I. 144.2: "Despachemos ahora a estos embajadores con la respuesta siguiente: que permitiremos que los megarenses utilicen nuestro mercado y nuestros puertos si a su vez los lacedemonios renuncian a las expulsiones de extranjeros que nos afectan a nosotros y a nuestros aliados [...]" (J.J. Torres Esbarranch).

${ }^{39}$ Cf. Momigliano, op. cit., p. 158.
} 
descontado, la situación personal de Pericles no constituiría el elemento principal pero sí debe tenerse en cuenta. ${ }^{40}$

En conclusión, podemos afirmar que la polarización del debate historiográfico sobre las verdaderas causas de la Guerra del Peloponeso tiene mucho que ver con los prejuicios que muestran los historiadores hacia las fuentes que abordaron la cuestión. En este sentido, abogamos por la armonización del relato recogido en Diodoro, inspirado en Éforo, y el ofrecido por Tucídides. Así pues, creemos incluso pernicioso defender que exista alrededor de la explicación de las causas una tradición tucidídea y otra no-tucidídea, conjunto que engloba fuentes tan dispares como Aristófanes, Diodoro y Plutarco. ${ }^{41} \mathrm{Al}$ respecto, hemos demostrado que los argumentos que presentan las fuentes no distan tanto entre sí como algunos historiadores nos quieren hacer ver y que el análisis de las causas de la guerra no pasa por estar a favor o en contra de Tucídides. En este sentido, creemos que la valoración en plano de igualdad de los testimonios antiguos que razonan sobre el origen de la guerra del Peloponeso puede aportar una visión de conjunto diferente y fresca, actualizando así un debate que lleva décadas en punto muerto.

\section{Bibliografía}

ADCOCK, F. E. Thucydides in book I. Journal of Hellenic studies, London, vol. LXXI, p. 2-12, 1951.

ANDREWES, A. Thucydides on the causes of the war. Classical quarterly, Oxford, vol. IX, t. II, p. 223-239, 1959.

BADIAN, E. From Platea to Potidea: studies in the history and historiography of the Pentecontaetia. Baltimore: The Johns Hopkins University Press, 1993.

CATALDI, S. Sulle origini e lo sviluppo della Lega Delia (478-461). In: AIGNER, L. (org.). Federazioni efederalismo nell'Europa antica: Bergamo, 21-25 settembre 1992. Milano: Vita e Pensiero, 1994, p. 117-159.

CAWKWELL, G. Thucydides and the Peloponnesian war. London: Routledge, 1997.

CONNOR, W. R. Thucydides. Princeton: Princeton University Press, 1984.

CORNFORD, F. M. Thucydides mythistoricus. London: Edward Arnold, 1907.

CRANE, G. Thucydides and the ancient simplicity. Berkeley/Los Angeles: University of California Press, 1998.

\footnotetext{
${ }^{40}$ Nunca debe olvidarse que Pericles sólo era la cabeza visible de una facción política con unos intereses determinados en la guerra (cf. Kagan, op. cit., p. 346-347). ${ }^{41}$ Esta división la vemos en Hornblower, op. cit., p. 111.
} 
DARBO-PESCHANSKI, C. The origin of Greek historiography. In: MARINCOLA, J. (org.). A companion to Greek and Roman historiography. Vol. 1. Malden: Blackwell, 2007, p. 27-38.

DIODORO DE SICILIA. Biblioteca histórica. Trad. J. J. Torres Esbarranch. Madrid: Gredos, 2006.

DIODORUS SICULUS. Diodorus of Sicily in twelve volumes with an English translation. Ed. and transl. by C. H. Oldfather. Vol. 4-8. Cambridge, Mass.: Harvard University Press, 1989.

FINLEY, M. I. El imperio ateniense: un balance. In: FINLEY, M. I. La Grecia antigua. Trad. T. Sempere. Barcelona: Crítica, 1984 [1978], p. 60-84.

GOMME, A. W. A historical commentary on Thucydides. Vol. 1. Oxford: Clarendon Press, 1945.

GRUNDY, G. B. Thucydides and the history of his age. Vol. 1. Oxford: Blackwell, 1947.

HOEKSTRA, K. Thucydides and the bellicose beginnings of modern political theory. In: HARLOE, K; MORLEY, N. (org.). Thucydides and the modern world: reception, reinterpretation and influence from the Renaissance to the present. New York: Cambridge University Press, 2012, p. 25-54.

HORNBLOWER, S. A commentary on Thucydides. Vol. 1. Oxford: Oxford University Press, 1991.

KAGAN, D. The outbreak of the Peloponnesian war. Ithaca: Cornell University Press, 1969.

KIRKWOOD, G. M. Thucydides' words for “cause”. American journal of philology, Baltimore, vol. LXXI, t. I, p. 37-61, 1952.

LENDON, J. E. Athens and Sparta and the coming of the Peloponnesian war. In: SAMONS, L. J. (org.). The Cambridge companion to the age of Pericles. New York: Cambridge University Press, 2007, p. 258-281.

LEWIS, D. M. The Archidamian war. In: LEWIS, D. M. et alii (org.). Cambridge ancient history. Vol. 5. Cambridge: Cambridge University Press, 2008, p. 370-432.

LOW, P. The Athenian empire. In: BOYS-STONES, G.; GRAZIOSI, B.; VASUNIA, P. (org.). The Oxford handbook of Hellenic studies. New York: Oxford University Press, 2009, p. 65-76.

MARTÍNEZ LACY, R. Historiadores e historiografía de la Antigüedad clásica. México: Fondo de Cultura Económica, 2004 [1994].

MATTINGLY, H. B. The Methone decree. Classical quarterly, London, vol. XI, t. II, p. 154-165, 1961.

MEIGGS, R. The Athenian empire. Oxford: Clarendon Press, 1972.

MEIGGS, R. Trees and timber in the ancient Mediterranean world. New York: Oxford University Press, 1982.

MEIGGS, R.; LEWIS, D. A Selection of Greek historical inscriptions: to the end of the fifth century B.C. Oxford: Oxford University Press, 1969. 
MOMIGLIANO, A. Algunas observaciones sobre las causas de la guerra en la historiografía antigua. In: MOMIGLIANO, A. La historiografía griega. Trad. J. M. Gázquez. Barcelona: Crítica, 1984 [1954], p. 151-167.

MORAIS-MOTA, C. C. As lições da história universal da "Biblioteca Histórica” de Diodoro de Sicília como processo educativo da humanidade. Tese de doutorado inédita. São Paulo: FFLCH-USP, 2008.

OBER, J.; DEROW, P.; GIARDINA, A.; MCLYNN, N.; WELCH, K. Personal perspectives. In: ERSKINE, A. (org.). A companion to ancient history. Oxford: Blackwell, 2009, p. 1-10.

PARMEGGIANI, G. Eforo di Cuma: studi di storiografia greca. Bologna: Pàtron, 2011.

PEARSON, L. Prophasis and aitia. Transactions of the American philological association, Atlanta, vol. LXXXIII, p. 205-223, 1952.

PODLECKI, A. J. Perikles and his circle. London: Routledge, 2011 [1998].

PRICE, J. J. Thucydides and the internal war. Cambridge/ New York: Cambridge University Press, 2001.

RAWLINGS, H. A semantic study of "Prophasis" to 400 b. C. Stuttgart: Franz Steiner, 1975.

RENGAKOS, A. Thucydides' narrative: the epic and herodotean heritage. In: RENGAKOS, A.; TSAKMAKIS A. (org.). Brill's companion to Thucydides. Leiden: Brill, 2006, p. 279-300.

DE ROMILLY, J. Thucydides and the Athenian imperialism. Oxford: Basil Blackwell, 1963 [1947].

ST. CROIX, G. E. M. The origins of the Peloponnesian war. London: Duckworth, 1972.

SACKS, K. S. Diodorus Siculus and the first century. Princeton: Princeton University Press, 1990.

SAMOTTA, I. Herodotus and Thucydides in Roman republican historiography. In: FOSTER, E.; LATEINER, D. (org.). Thucydides and Herodotus. New York: Oxford University Press, 2012, p. 345-378.

SCHWARTZ, E. Diodoros. In: PAULY, A.; WISSOWA, G. (org.). Paulys Realencyclopädie der classischen Altertumnswissenschaft. Vol. V (1). Stuttgart: J. B. Metzlersche, 1903, col. 663-704.

SEALEY, R. Thucydides, Herodotos, and the causes of the war. Classical quarterly, London, vol. II, t. I, p. 1-12, 1957.

SHANSKE, D. Thucydides and the philosophical origins of history. New York: Cambridge University Press, 2007.

SIERRA, C. La otra Pentecontecia. Ágora: estudos clássicos em debate, Aveiro, vol. XIV, p. 81-106, 2012a.

SIERRA, C. Nuevamente de Heródoto a Tucídides. Historiae, Barcelona, vol. IX, p. 71-87, 2012b.

SIERRA, C. Sobre la malevolencia hacia Diodoro en la historiografía moderna. Calíope: presença clássica. Rio de Janeiro (en prensa). 
STADTER, P. A. Thucydides as "reader" of Herodotus. In: FOSTER, E.; LATEINER, D. (org.). Thucydides and Herodotus. Oxford: Oxford University Press, 2012, p.39-68.

SULIMANI, I. Diodorus' mythistory and the pagan mission: historiography and culture-heroes in the first pentad of the Bibliotheke. Leiden: Brill, 2011.

THUCYDIDES. "Historiae" in two volumes. Ed. H. Stuart-Jones and J. E. Powell. Oxford: Oxford University Press, 1942.

TUCÍDIDES. Historia de la guerra del Peloponeso. Trad. J. J. Torres-Esbarranch. Madrid: Gredos, 2000.

TRITLE, L. A. A new history of the Peloponnesian war. Malden: Blackwell, 2010.

TUPLIN, C. H. Thucydides I 42.2 and the Megarian decree. Classical quarterly, London, vol. LXXIII, p. 301-307, 1979. 